\section{Correlation coefficients corrected for missing data}

\section{ROBERT MAYS}

Civil Service College, London, England SWIV IRB

Suppose one has full information on $\mathrm{N}$ individuals and $X$ variables and he takes a sample $S$ of these individuals and measures them on a further $Y$ variables. The correlation matrix for all $X+Y$ variables can be computed, but only for extracted sample $S$. The purpose of this paper is to describe a method and computer program that will provide an estimate of the full correlation matrix for all $\mathrm{N}$ individuals.

If $\mathrm{S}$ is taken at random from $\mathrm{N}$, the expected values in the correlation matrix are unchanged; but often, subjects are not selected for further study on this basis. For example, in selecting personnel, initial screening tests may be used to decide who proceeds to the next stage in the procedure (see Mays, 1976). Not only are scores on the "explicit" selection variables (X) higher in the selected group, but variables correlated with the screening tests will also be affected. Tests (Y) given at the next stage in the procedure are likely to have lower correlations with $\mathrm{X}$ within the selected sample $\mathrm{S}$ as compared with the whole group of $\mathrm{N}$ individuals. Alternatively, one may have data from a population census and use it to select a sample that has particular characteristics. A sample is often "implicitly" selected on other variables (Y) as well.

Let the full data matrix D be partitioned as follows:

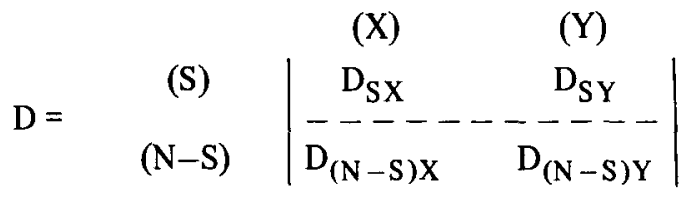

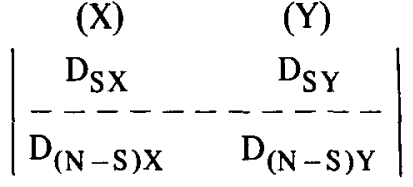

$\mathrm{D}_{(\mathrm{N}-\mathrm{S}) \mathrm{Y}}$ is unknown; let:

$V_{S X}=$ Variance-covariance matrix for the sample: $\left|D_{S X}\right|$

$\mathrm{V}_{\mathrm{NX}}=$ Variance-covariance matrix for all $\mathrm{N}: \mid \mathrm{D}_{\mathrm{SX}}$ $\left|D_{(N-S) X}\right|$

$\mathrm{C}_{\mathrm{S}}=$ Covariance matrix between $\mathrm{X}$ and $\mathrm{Y}$ for sample $\mathrm{S}$.

$\mathrm{C}_{\mathrm{N}}=$ Covariance matrix between $\mathrm{X}$ and $\mathrm{Y}$ for all $\mathrm{N}$.

Assuming that linear regression is appropriate for estimating $\mathrm{Y}$ from $\mathrm{X}$, then:

$$
R_{S}^{T}=C_{S}^{T} V_{S X}^{-1}
$$

and

$$
\mathrm{R}_{\mathrm{N}}^{\mathrm{T}}=\mathrm{C}_{\mathrm{N}}^{\mathrm{T}} \mathrm{V}_{\mathrm{NX}}^{-1}
$$

where $R_{S}=$ matrix of regression weights for predicting each $\mathrm{Y}$ variable from the set of $\mathrm{X}$ variables in sample $\mathrm{S}$; similarly for $\mathrm{N}, \mathrm{T}$ indicates the matrix transpose.

Although $\mathrm{C}_{\mathrm{N}}$ is unknown, it can be estimated if it is assumed that the properties of the regression of $\mathrm{Y}$ on $X$ are identical for both $S$ and $N$ (see Gulliksen, 1950); that is,

$$
\mathrm{R}_{\mathrm{S}}^{\mathrm{T}}=\mathrm{R}_{\mathrm{N}}^{\mathrm{T}}
$$

Equations 1,2, and 3 yield:

$$
\mathrm{C}_{\mathrm{N}}=\mathrm{V}_{\mathrm{NX}} \mathrm{V}_{\mathrm{SX}}^{-1} \mathrm{C}_{\mathrm{S}}
$$

and

$$
\mathrm{V}_{\mathrm{NY}}=\mathrm{v}_{\mathrm{SY}}+\mathrm{C}_{\mathrm{S}}^{\mathrm{T}} \mathrm{V}_{\mathrm{SX}}^{-1}\left(\mathrm{C}_{\mathrm{N}}-\mathrm{C}_{\mathrm{S}}\right)
$$

where $V_{N Y}$ is the variance-covariance matrix for the $Y$ variables in $N$. Since $V_{N X}$ can be computed from the data, the whole variance-covariance matrix for all $\mathrm{N}$ and $\mathrm{X}+\mathrm{Y}$ is:
$(\mathrm{X}) \quad(\mathrm{Y})$
The correlation matrix follows directly from the covariance matrix. The program described below includes computation of this matrix, together with the corrected means and standard deviations.

Input/Output. Three raw data matrices are required as input: $\mathrm{D}_{\mathrm{SX}}, \mathrm{D}_{\mathrm{SY}}$, and $\mathrm{D}_{(\mathrm{N}-\mathrm{S}) \mathrm{X}}$. Output options include means, standard deviations, and full correlation matrices for the following data sets: (a) selected sample $S$, all $X$ and $Y$ variables; (b) nonselected sample $\mathrm{N}-\mathrm{S}, \mathrm{X}$ variables only; (c) whole group $\mathrm{N}$, all $\mathrm{X}$ and Y variables.

Computer, Language, and Restrictions. The program is written in BASIC and versions are available for use on IBM CALL/360 and Honeywell Mark 3 timesharing systems.

Availability. Copies of this paper and a source listing of the program are available at no charge from Robert Mays, Civil Service College, 11 Belgrave Road, London, England SWIV 1RB.

\section{REFERENCES}

Gulliksen, H. Theory of mental tests. New York: Wiley, 1950. Mays, R. Multivariate analysis in personnel selection. Educational and Psychological Measurement, 1976, 36, 905-912. 